\title{
Uzbek mythology and shamanism
}

\author{
Kayumov Olim Sadiridinovich \\ Candidate of Philological Sciences (Uzbekistan)
}

\begin{abstract}
There is a lot of debate about the myth, its specificity, and essence of the meaning of this term. The article contains information about various doctrines. And under the influence of these teachings we can see that the classification of myths has taken place. The well-known Uzbek folklorist M. Juraev emphasized that the myth was the first conscious notion of the occurrence of natural phenomena of our ancient ancestors [10.p.12.].
\end{abstract}

Key words: the myth, folklorist, genre of oral poetic creation, ethnography, shamanic rituals, mythological plots.

\section{I.Introduction}

In the field of folklore and ethnography, myth is a separate genre of oral poetic creation [1.p.200.]. We call this kind of set of verbal sayings and imaginations mythology in science. The sayings of Uzbek shamanic rituals, by their nature, form a separate category of mythological sayings. The sayings performed by shamans during the ceremonial process are essentially a series of purely mythological sayings. N.A. Alekseev, who discovered the existence of mythological plots and motives in Yakut folklore, classified the shamanic myths separately [2.p.9.].

\section{II.Literature review}

In his classification, N.A. Alekseev divides the myths contained in folk mantles into six main groups:

1) myths about fish, animals and birds,

2) myths about the rulers of the blue world, celestial bodies and the sky,

3) another world, including the middle world (on earth) myths about beings,

4) myths about the spirits of the underworld,

5) myths about the ancestors of the first ancestors of man,

6) myths about shamanism.

Apparently, the classification carried out by $\mathrm{N}$. Alekseev is based on the description of myths in all folklore texts. However, the myths about the existence of other worlds in the middle world and the spirits of the lower world, as well as the myths about the first ancestors of man, are difficult to distinguish from the myths of shamanism, (ghost, yellow girl), the spirits of the underworld (spirits of the dead) are also included, so the classification of myths in this parable does not justify itself.

\section{III.Analysis}

In the folklore of shamanic rituals of the Turkic peoples, the main mythological patrons of the shaman are the ancestors, the spirits of the dead, the dead saints, and the shaman's contemporaries, the pirs, who are still alive and have divine power(fairies, yellow girl), Hizr [11.pp.90-93.], a mythological patron who drank the water of life and warned all mankind against calamities and helped humanity in difficult times.

Given the impossibility of covering all the issues related to the specificity and transformation of myths in a short article, we found it necessary to dwell on which parts of the existing myths in Uzbek mythology are related to shamanism.

In the scientific literature, the shaman is the mediator between the people and the representatives of the unseen world [6.p.124; 13.pp.18-24; 4.p.289; 5.p.127; 12.p.47.]. At present, in almost all regions of the country, patients are often treated by neighbors, fortune tellers, and patients turn to them. Shamans play an important role in transmitting and preserving folk mythology to future generations.

Shamanism has a special place in the system of different ethnicities and religious beliefs. It should be noted that shamans are not the founders of Uzbek mythology, but the bearers and popularizers of certain mythological ideas. "The main sign of shamanism is the belief that the chosen, trained people are in contact with spirits, as well as their divine 
power, through spirits" [3.c.32.]. It was noted by S.A. Tokarev that the term "shaman", which means "crazy quality", is derived from the word "straw" in the Tungus-major language [14.p.262].

According to the Uzbek shaman, there are spirits. The spirits of the dead always watch over their loved ones. Most of the mythological patrons of bakhshi, porikhan, fortune tellers and neighbors are the spirits of the dead. For example, in the sayings of Uzbek shamans, Anbar mother is mentioned as a mythological patron, and the shaman worships Anbar mother. It was stated in our research that Anbar was a native historical figure who lived in a specific historical period [16.pp.35-38.]. Similarly, in the sayings of shamanic rituals, the mythological patrons of shamans are saints, prophetic individuals who have lived in history.

It should be noted that the cults of fathers, grandfathers and grandmothers, who come as mythological patrons of Uzbek shamans, form a separate group. The notion of prophetic historical figures as myths after their deaths must be interpreted in relation to the common, traditional criteria of the shamanistic belief of all peoples. In both the Tuva shamanic sayings and the Altai Turkic shamanic sayings, the cults of the late fathers and mothers come as mythological patrons of the shaman [8.pp.147-148; 7.p.3; 9.pp.26-56.].

In the texts of Uzbek shamanic folklore written by us, the belief in the existence of spirits, the spirits are representatives of the unseen world, but can affect the earthly world. This belief was shaped as a separate myth, and only the parhans, kushnoch, and bakhshis had a complete idea of their essence. In particular, the fact that fairies are beings from another world, that they belong only to those they have chosen, was known only to those who were aware of shamanism. Ordinary people considered fairies to be human beings who were sometimes evil, sometimes good.

The views of our people about spirits, especially fairies and demons, are more vividly reflected in the poetics of shamanic legends than in mythological legends. It is also observed in shaman legends that not only mythological characters such as faerie and Hizr, but also ancestral cults are mentioned as mythological patrons of shamans.

The myths that are artistically perceived in the legends of Uzbek shamans can be grouped as follows:

a) the myth that a person acquires the profession of shaman. The memory of the late Jangil Bakhshi Akhmedova is in great pain before she receives the shamanism, and the gods appear to her in the form of a black ram with curly horns, signaling that a ram will be sacrificed and taken from him;

b) myths about shamanic utensils (whistle, whip, amulet, fetish, knife, book).

The late fortune teller Shamsiya momo Ashurova from Karmana gets a Turkmen faerie when she gets a book inherited from her grandmother as a child and drives the girl crazy. Later, his relatives noticed him and made Shamsia a bakim (shaman ritual) and put him in a chilla. After leaving Chilla, she acquires the profession of fortune-teller with the permission of the spirits. A similar adventure occurs in the plot of a shaman legend told by a black neighbor Bakhmal momo, who lives in the village of Tim, Nurabad district, Samarkand region. At the age of thirty, the velvet grandmother carries a whip and a whip left by the late neighbor grandmother. From that day on, she suffered from severe pain in her limbs.

She has been in pain for a long time and suffers from constant pain. A few years later, in a dream, a neighbor kills a grandmother, invites her to a circle of grandmothers, and tells her that she is going to slaughter a living creature (an animal, such as a sheep) and sacrifice it, and take her hand as a grandmother. After that, Bakhmal momo heals by following the instructions of those who came in the dream and takes up the profession of shamanism. Legends of this type are dominated by the extraordinary power of shamanic devices, the motif of which these devices associate shamans with spirits;
c) Myths about shaman patrons;
d) Myths about the spirits of the deceased shaman.

\section{IV.Discussion}

In the myths associated with shamanism, the shaman is interpreted as an earthly person chosen by the spirits, i.e., representatives of another world, and nurtured by them. According to popular belief, a shaman's mastery of the shamanic profession is caused by great difficulty and hardship, heavy suffering and death, and eventually by the fact that the spirits extend a helping hand to the patient, bring him back to life and give him the responsibility to perform shamanic deeds.

Memory Tolganoy Mirzaeva lost her limbs when she was 16 years old. There is no clear diagnosis in the observations made by the medical staff. Every doctor treats them with medication as they see fit. The patient's condition is getting worse day by day. The patient's teeth fall out. In this condition she suffers for eight years. One day, her brother 
Samad, who felt sorry for her paralyzed sister at home, picked her up and took her to the porch. When he says she feels much better in her chair, her brother goes to water his cattle. Meanwhile, no one stays in front of Tolganoy for an hour. In front of the girl, who was left alone, a group of fairy girls appeared and stroked her limbs.

The fairies disappear, telling him that he needs to get a circle, keep a tent, and treat patients like her. The next day, Tolganoy begged her mother and appeared to her. When Bakhshi sees a fortune-teller, she tells her that the fairies are acquainted with him, that he is through her (a representative of another world, a patron of mythological power), that he is suffering because she is chosen by the spirits and does not want to obey them. After nursing, the patient gradually begins to recover. In particular, she walks away when she has achieved complete shamanism.

It is clear from the above information that the shaman's affliction with shamanic disease was that her spirit was abducted by the spirits and nurtured by the representatives of the unseen world. According to N.A. Aleseev, the same situation is observed in ruby shamans [1.c.108.]. How long the future shaman will be brought up, that is, how long he will be in pain, will be determined only by the representatives of the unseen world.

At the end of the period set by the shamanic summoning spirits, the patient will be able to recover, see the past and possible future events, communicate with representatives of the unseen world, and be able to send their patron spirits to any place. The shaman acts as a spiritual mediator between gods, spirits, and humans.

Shamans predict the health of people, the influence of evil spirits, their future, happiness and tragedy, the whereabouts of lost people or objects, it is imagined that spirits will help him in this way. Shamans always call on spirits to do their deeds. Even if they see a fortune-teller to find something, they will certainly summon the patron spirits and discuss the matter in their circle. Nasiba-opa, a bakhsh from Navoi, calls her grandparents and great-grandparents. When the "saints" visit, they communicate with them and discuss the issue. For example, if a person asks a question about the future, Bakhshi describes the future reality in the language of the author (as they said, as they said).

Sometimes the shaman encourages himself/herself to take on the image of the patron spirits while calling them. Shoira Haqberdieva, a resident of Navbahor district, calls her grandmother and niece during the ceremony and turns around like an old woman. Remembrance Tolganoy Mirzaeva performs Hindi dance moves when calling Hindu fairies.

According to popular belief, shamans are aided by many spirits. During the folklore expeditions conducted by us, interesting information was recorded about the number and names of patrons of Uzbek shamans, as well as their tasks. T. Mirzaeva said that she had more than two hundred thousand patron saints. [15.p.43] Sh. Haqberdieva from Navbahor mentioned the names of twenty-seven patron saints. [15.pp.41-42]

The mythological characters of demonological nature, such as the demon, yellow girl, mortu, gin, genie, which exist in Uzbek mythology, in fact appeared as an evil force, an evil spirit that leads man to destruction. According to A. Ashirov, "The ancestors of the Turkic peoples strongly believed in the existence of faeries, ancestors, grandmothers, as well as giants and demons" [3.p.29].

\section{V.Conclusion}

From the above, it is clear that the most common mythological characters in Uzbek mythology are: faerie, gin, genie, hellcat, yellow girl, night-hag, bogy, Hizr and the spirits of saints, the spirits of the dead, etc. This shows the role of the Shamanic faith in the formation of Uzbek mythology. Mythological ideas play an important role in the development of oral poetic creativity, poetic thinking in general.

As a result of the evolution of mythological characters, that is, their transition from one state to another, their magical power was absorbed into the epic, lyrical works created orally at different times, the artistic properties of literature were enriched and perfected.

\section{References:}

\# Alekeev N. A. Traditional religious beliefs of the Yakuts in the 19th - early 20th centuries. - Novosibirsk: Nauka, 1975.200 p.

* Alekseev N.A. Yakut mythology and shamans // Institute of Archeology and Ethnography SB RAS, Novosibirsk, 1995.9p

\# Ashirov A. Ancient beliefs and ceremonies of the Uzbek people. Alisher Navoi National Library of Uzbekistan, Tashkent, 2007. 
\# Basilov V.N Pari // myths of the peoples of the world -T.2.-M.1989.289p;

* Bertels E. Peri // Culture and arts of the peoples of Central Asia in antiquity and the Middle Ages. M., 1979.127p;

* Bulatov A.O. Relects of Shamanism among the peoples of Dagestan // SE1991.-124p;

* Dyakonova V.P. Objects for the healing function of shamans of Tuva and Altai // Material culture and mythology. Collection of the Museum of Anthropology and Ethnography XXXVII. L .: Nauka, 1981.147148pp;

* Ivanov S.V. Elements of protective armor in shamanic clothes of the peoples of Western and Southern Siberia // Ethnography of the peoples of Altai and Western Siberia. Novosibirsk, 1978.

* Juraev M. Uzbek mythology and Arabic folklore. Tashkent, Fan, 2000.

\# Kayumov O. The image of a fairy (genesis and poetics) in Uzbek folklore. Nomz diss. Tashkent, 1999. 43p.

* Kayumov O. Ancestor cult in Uzbek shaman folklore. Anbar ona // Proceedings of the XXIII scientificpractical conference of professors-teachers and students. Section 3. Navoiy 2008. 35-38pp.

* Nurmonov F.I. On the epic appearance of the image of Hizr // Proceedings of the Republican scientifictheoretical conference "New principles of studying the Uzbek ceremonial folklore." Navoi, 2007.-pp 90-93.

* Sukhareva O.A. Remnants of demology and shamanism among equal Tajiks // Pre-Muslim beliefs and rituals in Central Asia. M., 1976. 47p.

* Taijanov K., Ismoilov H. Peculiarities of pre-Islamic beliefs among Uzbeks-Karamurts // Ancient rituals, beliefs and cults of Central Asia. M., 1986. 118-120pp.

\# Tokarev S.A. Early forms of religion. Moscow, Politizdat, 1990. 262p.

* Weinstein S.I. Tuvan shamanism. M., 1964.3p;

\$ 17.www.ruthina.ru 